\title{
215 INCIDENCE AND CHARACTERISTICS OF ANKLE INJURIES IN PROFESSIONAL FEMALE FUTSAL, BASKETBALL, VOLLEYBALL AND HANDBALL PLAYERS
}

Aazam Barani, Nader Rahnama, Effat Bambaeichi Faculty of Physical Education and Sport Sciences, University of Isfahan, Isfahan, Iran

10.1136/bjsm.2010.078725.215

Ankle injury is one of the most common sports injuries in contact sports. The purpose of this study was to investigate incidence and characteristics of ankle injuries among female futsal, basketball, volleyball and handball players (20062007). The information related to injury were collected using injury report forms that completed by team physicians. $\chi^{2}$ Test was used for analyses. Out of 287 players who participated in this study 40 ankle injuries were reported from that $67.5 \%$ were ankle sprain. Most of ankle injuries occurred in volleyball (35\%) and basketball (32\%), futsal (22.5\%) and lowest in handball $(10 \%)\left(\chi^{2}=6.2, p>0.05\right)$. The majority of ankle injuries occurred via landing $(60 \%)$ and cutting and changing direction $(27.5 \%)\left(\chi^{2}=14.1, \mathrm{p}<0.05\right)$. The most of injuries occurred by contact $(57.5 \%)$, special contact to other player $(78.3 \%)\left(\chi^{2}=0.9, p>0.05\right)$. About $50 \%$ of ankle injuries were not associated with previous injury, but were recurrent injury in this season (57.5\%). Players who played more than 4 years as a professional athlete sustained more injuries, and they also have more previous injuries $\left(\chi^{2}=0.5, p>0.05\right)$. Centres in basketball, spikers in volleyball and line players in handball sustained more ankle injuries. It can be concluded that the rate of ankle injuries in sports with landing and cutting manoeuvre is high, in special in professional players whom perform these manoeuvres more than others. These data are useful for preventive programmes and to reduce rate of ankle injuries in sports. 